\title{
PELANGGARAN PRINSIP KERJA SAMA DALAM ACARA THE COMMENT DI NET TV
}

\author{
Adi Hermawan, Sri Budi Astuti \\ (Pendidikan Bahasa dan Sastra Indonesia, Fakultas Keguruan dan Ilmu Pendidikan, \\ Universitas PGRI Adi Buana Surabaya) \\ adihermawan48@gmail.com, sri.budi@unipasby.ac.id
}

\begin{abstract}
ABSTRAK
Penelitian ini dilatarbelakangi oleh acara humor yang berbeda dengan acara humor lainnya. Komentar merupakan acara baru, acara humor tanpa sarkasme atau cemoohan dalam sebuah informasi, yang baru-baru ini mendapat teguran dari Komisi Penyiaran Indonesia (KPI). Tujuannya adalah untuk mendeskripsikan pelanggaran maksim kerja sama yang meliputi maksim kuantitas, maksim cara, maksim relevansi, dan maksim cara, sebagai sarana untuk menciptakan humor dalam acara The Comment on Net TV pada Agustus 2016. Penelitian ini merupakan penelitian deskriptif kualitatif. Subjek dalam penelitian ini disajikan adalah pidato dalam acara yang melanggar prinsip kerja sama. Data diperoleh dengan merekam peristiwa The Comment kemudian ditranskripsikan dalam bentuk wacana tertulis. Teknik analisis data yang digunakan dalam penelitian ini adalah teknik deskriptif kualitatif. Validitas data menggunakan teori triangulasi. Hasil dari penelitian ini adalah deskripsi pelanggaran prinsip kerja sama dalam acara The Comment on Net TV pada bulan Agustus 2016. Ditemukan total 12 ucapan pelanggaran meliputi 4 ucapan maksim kuantitas, 4 ucapan maksim kualitas, maksim relevansi 4 tuturan dan maksim cara 4 tuturan.
\end{abstract}

Kata kunci: prinsip kerjasama, maksim, humor.

\section{PENDAHULUAN}

Peran bahasa sangat penting dalam kehidupan sehari-hari, bahasa digunakan sebagai alat komunikasi antara anggota masyarakat berupa simbol bunyi yang dihasilkan oleh alat ucap manusia. Menurut Kridalaksana dan Djoko Kentjono (dalam Chaer, 2007: 32), bahasa adalah lambang bunyi yang arbitrer yang digunakan oleh para anggota masyarakat sosial untuk bekerja sama, berkomunikasi dan mengidentifikasi diri. Pendapat lain mengatakan bahasa adalah suatu sistem komunikasi yang menggunakan simbol vokal yang bersifat arbitrer, yang dapat diperkuat dengan gerakgerik badan yang nyata (Keraf, 2004:2). Kedua pendapat di atas dapat diketahui bahwa pengertian bahasa adalah suatu alat komunikasi yang bersifat arbitrer yang di dalamnya berupa simbol-simbol vokal dan didukung dengan gerak-gerik badan yang nyata.

Dalam perkembangannya bahasa selain digunakan sebagai alat komunikasi sekarang banyak dimanfaatkan untuk menghibur bagi pendengarnya. Banyak stasiun TV yang memanfaatkan bahasa sebagai sarana hiburan, salah satunya adalah program The Comment yang digagas oleh Net TV. Salah satu dari program yang akan diteliti adalah program The Comment. The comment adalah salah satu program unggulan Net TV yang disiarkan setiap hari Senin- Jum'at mulai pukul 22.00- 23.00 WIB . Net TV sendiri adalah stasiun televisi baru yang didirikan oleh seorang mantan karyawan Trans Corps Wishnutama 
bersama Agus Lasmono, seorang pengusaha batubara yang juga pendiri Indika Grup. Stasiun televisi ini resmi di launching pada 26 Mei 2013 lalu.

The comment merupakan sebuah tayangan komedi dibawakan oleh duo komik Indonesia Dimas Danang dan Imam Darto. Acara ini menampilkan video sebagai bahan obrolan mereka. Kebanyakan yang ditayangkan mengambil dari youtube. Sebenarnya acara seperti menampilkan video dari youtube telah banyak di tayangkan di berbagai stasiun TV nasional seperti $O n$ The Spot di Trans7, Fenomania di ANTV dan Hotspot di Global TV. Kelebihan dari program the comment adalah kekuatan host membuat penonton tertawa ketika mengomentari video yang baru saja di tampilkan. Komenter yang diucapkan Dimas Danang dan Imam Darto jauh dari kata serius dan kebanyakan di plesetan namun masih tetap dalam batasan yang norma kesopanan jadi aman ditonton untuk semua anggota keluarga. Berbeda dengan acara komedi yang ada saat ini yang kebanyakan berisi celaan dan menghina pemain lain agar terlihat lucu (Seandainya. 2014. Dua LakiLaki Pejaka. http://thecommentnettv.blogspot.co.id / Diunduh, 13 Agustus 2016).

Penjelasan di atas dapat diketahui mengenai bahasa yang digunakan dalam acara the comment di Net TV adalah bahasa plesetan atau humor. Sejalan dengan hal tersebut Sheinowist (dalam Darmansyah, 2010:66) menyatakan bahasa humor adalah suatu pesan bahasa atau kemampuan untuk menerima, menikmati, dan menampilkan sesuatu yang lucu, dan aneh namun bersifat menghibur. Adapun cara mengetahui ciri bahasa humor berkaitan dengan pelanggaran tiga hal, yakni ketidakpatuhan terhadap maksim percakapan, maksim kesopanan, dan parameter pragmatik yang terjabar ke dalam berbagai submaksimnya. Demikian juga pengertian tentang bahasa humor adalah pelanggaran terhadap aspek pragmatik yang telah disebutkan sebelumnya diperlukan untuk menciptakan kelucuan bagi pembaca atau pendengarnya (Wijana, 2004:33). Dari kedua pendapat di atas dapat disimpulkan bahwa bahasa humor adalah suatu tuturan yang melanggar aspek pragmatik yang dimaksudkan dengan tujuan untuk menghibur para penonton.

Selanjutnya diperoleh mengenai penelitian terdahulu, penelitian pertama dilakukan oleh Sutrisno (2015) dengan judul "Bahasa Banalitas pada Program The Comment di Net TV". Bahasa banalitas adalah omongan yang tidak berharga, omongan kosong saja, omongan sampah atau cemohan. Bahasa banalitas pada program the comment, misalnya saja dengan kata masa?? bodo!, siapa? yang nanya!!! dan lain sebagainya. Tujuan penelitian tersebut adalah untuk mengetahui Penandaan Bahasa Banalitas di Program The Comment di Net TV (Mercubuana, 2016).

Penelitian ke dua dilakukan Mayasari (2015) yang berjudul "Analisis Bahasa Plesetan dalam Tayangan The Comment di Net TV. Fokus penelitiannya pada pola pembentukkan bahasa yakni pemanjangan, subtitusi, reduplikasi, asimilasi, epentesis, sinkop, apokop, dan paragog (UMM, 2016).

Penelitian ke tiga dilakukan Waskitarini (2012) yang berjudul "Prinsip Kerja Sama yang Terjadi dalam Acara Opera Van Java di Trans 7. Fokus penelitiannya tentang pelanggaran prinsip kerja sama dan 
memadukan antara beberapa maksim yang terdapat dalam satu tuturan atau satu dialog. Kedua fokus penelitiannya berkaitan dengan tujuan tindak tutur, yakni tujuan tutur tindak representatif, tujuan tutur tindak direktif, tujuan tutur tindak ekspresif, dan tujuan tindak deklaratif (Waskitarini, 2012).

Berdasarkan penelitian terdahulu di atas yang kaitannya dengan acara The Comment dapat dilihat perbedaan jika pada penelitian pertama fokus penelitian pada bahasa banalitas (plesetan), penelitian kedua perbedaannya karena fokus penelitiannya pola pembentukkan bahasa, dan penelitian ketiga karena fokus penelitian pada pada pelanggaran prinsip kerja sama dan tujuan tidak tutur. Sehingga penelitian acara The Comment dengan menggunakan prinsip kerja sama sangat dimungkinkan sehingga dapat memperoleh hasil penelitian yang belum pernah ditemukan oleh peneliti lain. Dimana penelitian akan dilakukan dengan meneliti sauatu tuturan yang berkaitan dengan pelanggaran prinsip kerja sama yang meliputi 4 (empat) maksim: maksim kuantitas, maksim kualitas, maksim relevansi, dan maksim cara.

Alasan keinginan pemilihan prinsip kerja sama dalam penelitian ini dikarenakan keinginan untuk mengetahui penggunaan bahasa dalam acara The Comment yang mampu menimbulkan kelucuan dan menghibur para penonton. Berkaitan dengan itu, maka temuan yang diperoleh adalah tuturan yang berupa pelanggaran prinsip kerja sama dalam acara The Comment di Net TV. Dari penelitian ini diharapkan dapat digunakan sebagai bahan pengembangan penelitian berikutnya yang sesuai dengan prinsip kerja sama. Berdasarkan uraian latar belakang di atas, maka perlu diadakan penelitian dengan judul Pelanggaran Prinsip Kerja Sama dalam Acara The Comment di Net TV. Prinsip kerja sama meliputi 4 (empat) maksim yakni: maksim kuantitas, maksim kualitas, maksim relevansi, dan maksim cara.

Permasalahan berkaitan dengan bentuk pelanggaran prinsip kerja sama dalam acara The Comment di Net TV. Sehingga diperoleh pertanyaan penelitian tentang bagaimana bentuk pelanggaran prinsip kerja sama dalam acara The Comment di Net TV. Tujuan penelitian ini ada 4 yakni a) untuk memperoleh hasil deskripsi pelanggaran maksim kuantitas yang terjadi dalam percakapan acara The Comment di Net $\mathrm{TV}$, b) untuk memperoleh hasil deskripsi pelanggaran maksim kualitas yang terjadi dalam percakapan acara The Comment di Net TV, c) untuk memperoleh hasil deskripsi pelanggaran maksim relevansi yang terjadi dalam percakapan acara The Comment di Net TV, d) untuk memperoleh hasil deskripsi pelanggaran maksim cara yang terjadi dalam percakapan acara The Comment di Net TV.

\section{METODE PENELITIAN}

Penelitian ini merupakan penelitian deskriptif dengan pendekatan kualitatif. Data dalam penelitian ini berupa tuturan dalam bentuk kalimat yang berkaitan dengan pelanggaran prinsip kerja sama. Sumber data yang digunakan dalam penelitian ini adalah acara The Comment di Net TV, yang diperoleh melalui tayangan selama 1 bulan yakni pada tanggal 1 Agustus- 1 September 2016 (Arikunto, 2010: 172)

Pengumpulan data dalam penelitian ini digunakan metode simak 
karena cara yang digunakan peneliti untuk memperoleh data dilakukan dengan menyimak penggunaan bahasa. Teknik yang digunakan adalah teknik sadap, dengan teknik lanjutan simak bebas libat cakap, yang dilanjutkan dengan teknik rekam dan teknik catat (Sudaryanto, 1992:136).

Teknik analisis data yang dilakukan dalam penelitian ini menggunakan teknik padan. Teknik padan merupakan jabatan metode yang ditentukan oleh alat yang dipakai. Teknik padan digunakan dengan teknik dasar daya pilah referensial yakni, menggunakan referen atau sosok yang diacu oleh satuan kebahasaan sebagai alat penentu. (Sudaryanto, 1992:26). Dalam penelitian ini keabsahan data digunakan teknik triangulasi yakni triangulasi teori, triangulasi sumber, dan triangulasi metode.

\section{HASIL DAN PEMBAHASAN}

\section{A. Hasil penelitian}

1. Maksim Kuantitas

Di dalam maksim kuantitas menyatakan bahwa setiap peserta tutur hanya memberikan kontribusi secukupnya atau sebanyak yang dibutuhkan oleh lawan tuturnya. Jadi apabila informasi yang diberikan penutur kepada petutur melebihi informasi yang diperlukan, dapat dikatakan tuturan tersebut melanggar maksim kuantitas dalam prinsip kerja sama. Di dalam acara The Comment di Net TV pada bulan Agustus 2016, ditemukan data tuturan, yang akan dibahas sebagai berikut :

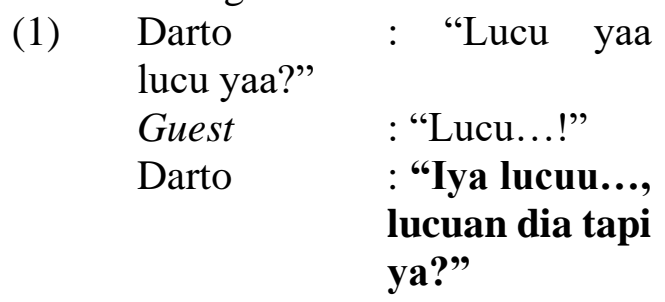

sihh ya"

Danang

:"Iya

Guest

:"Lucuan
kamu, sama
kamu!!
(The Comment
di r Net
TV/01/02-08-

16)

Konteks: Peristiwa terjadi saat mengomentari video yang sudah ditayangkan. Tuturan Darto mengaharapkan Guest juga sependapat bahwa video yang baru saja diputar memang lucu.

Berdasarkan tuturan (1), informasi yang diberikan Darto melebihi informasi yang diperlukan oleh petutur, yakni pada kalimat "Iya Lucu..., lucuan dia tapi ya". Adanya penambahan kalimat "Lucuan dia tapi ya" menunjukkan adanya pelanggaran maksim kuantitas.

Ditemukan juga bentuk lain pelanggaran maksim kuantitas dalam acara The Comment di Net TV pada bulan Agustus 2016 adalah berikut ini.

(2)

$\begin{array}{rlr}\text { Guest } & \text { "Kalau } \\ & \text { ditikung kan } \\ & \text { sakit banget, } \\ & \text { kalau nikung } \\ & \text { kan } \quad \text { dari } \\ & \text { kemauan kita." }\end{array}$

Danang

$$
\begin{aligned}
& \text { "Bukan,,kala } \\
& \text { u ditikung } \\
& \text { sakit itu kan } \\
& \text { salah } \\
& \text { orangnya, } \\
& \text { kalau saya } \\
& \text { ditikung ya } \\
& \text { nggak sakit, } \\
& \text { jalan lagi sama } \\
& \text { yang baru } \\
& \text { selow." }
\end{aligned}
$$

Darto dan Guest

"Yuuuutttttt sedeppp..." 


\section{(The Comment di Net TV/07/04-08-}

16)

Konteks: Peristiwa terjadi pada saat Guest memberikan pernyataan tentang seseorang yang selingkuh. Selanjutnya ditanggapi Danang dengan komentar yang menyimpang.

Berdasarkan tuturan

Danang memberikan kontribusi yang berlebihan dari informasi yang diminta oleh Guest, terbukti pada kalimat "Jalan lagi sama yang baru selow" yang menunjukkan adanya pelanggran maksim kuantitas.

\section{B. Pembahasan}

Berdasarkan hasil penelitian pelanggaran prinsip kerja sama dalam acara The Comment di Net TV yang didukung dengan menggunakan metode padan telah diperoleh beberapa temuan data tuturan yang dianggap melanggar prinsip kerja sama. Data yang diperoleh kemudian dikelompokkan ke dalam 4 (empat) maksim, maksim kuantitas, maksim kuantitas, maksim relevansi, dan maksim cara. Hasil yang diperoleh merupakan penerapan berdasarkan teori Grice tentang prinsip kerja sama. Penerapan dengan menggunakan teori Grice tentang prinsip kerja sama dalam analisis penelitian acara The Comment merupakan penemuan baru dalam hal objek yang dikaji, karena penelitian sebelumnya menunjukkan bahwa belum ada peneli yang menggunakan objek acara The Comment yang analisisnya dengan menggunakan prinsip kerja sama.

Prinsip kerja sama merupakan bentuk tuturan yang memudahkan seseorang dalam berkomunikasi untuk mencapai suatu tujuan atau maksud yang ingin disampaikan kepada petutur. Dalam kehidupan sehari-hari sebenarnya pelanggaran tentang prinsip kerja sama sangat sering dilakukan dalam konteks berkomunikasi, akan tetapi tidak semua orang mengetahuinya. Hanya mereka yang ahli di bidang bahasa yang mengetahui. Pelanggaran prinsip kerja sama sering terjadi bisa di sekolah, di rumah ataupun di tempat kerja, contohnya sederhana adalah teman di sekolah yang suka bercanda dalam bertutur atau berkomunikasi dengan teman lainnya. Tuturan tersebut dapat dikatakan melanggar prinsip kerja sama karena biasanya orang yang bercanda tuturan yang diucapkan tidak sesuai dengan apa yang seharusnya diharapkan oleh petutur. Jadi kesimpulannya bahwa seseorang yang tidak mematuhi atau melanggar prinsip kerja sama dapat membuat informasi tersebut tidak secara penuh tersampaikan, ataupun bisa menimbulkan kelucuan yang bergantung dengan konteks pada saat berkomunikasi.

\section{SIMPULAN}

Berdasarkan hasil penelitian
pembahasan mengenai
dan prinsip kerja sama dalam
pelanggaran prian
acara The Comment di Net TV pada
bulan Agustus 2016, dapat
disimpulkan bentuk pelanggaran
prinsip kerja sama dalam acara The
Comment di Net TV meliputi 4
(empat) maksim, yaitu maksim
kuantitas, maksim kualitas, maksim
relevansi, dan maksim cara.
1. Maksim kuantitas adalah bentuk
tuturan yang menghendaki setiap
peserta tutur hanya memberikan
kontribusi secukupnya saja atau
sebanyak yang dibutuhkan oleh
lawannya.


2. Maksim kualitas adalah bentuk tuturan yang menghendaki agar peserta tuturan mengatakan hal yang sebenarnya, hal yang sesuai dengan data dan fakta. Kecuali barangkali memang tidak tahu.

3. Maksim relevansi adalah bentuk tuturan yang mengharuskan setiap peserta petuturan memberikan kontribusi yang relevan dengan masalah atau tajuk pertuturan.

4. Maksim cara adalah bentuk tuturan yang mengharuskan penutur dan lawan tutur berbicara secara langsung, tidak kabur, tidak ambigu, tidak berlebih-lebihan dan runtut.

\section{SARAN}

Berdasarkan simpulan di atas, penelitian ini dapat diikemukakan saran sebagai berikut:

1. Untuk memberi petunjuk atau arahan kepada tim kreatif acara The Comment tentang penggunaan bahasa yang kaitannya dengan pelanggaran prinsip kerja sama yang meliputi 4 (empat) maksim yaitu maksim kuantitas, maksim kualitas, maksim relevansi, dan maksim cara.

2. Penelitian ini diharapkan dapat menindaklanjuti penelitian serupa dengan aspek yang berbeda, yang dapat digunakan sebagai acuan atau tolak ukur dalam penelitian lain yang masih berkaitan dengan pelanggaran prinsip kerja sama 1/artikel/1212/36/204 kerja sama yang meliputi 4 (empat) maksim yaitu maksim kuantitas, maksim kualitas, maksim relevansi, dan maksim cara.

\section{DAFTAR PUSTAKA}

Arikunto, Suharsimi, 2010. Prosedur Penelitian Suatu Pendekatan Praktik. Jakarta: Rineka Cipta.

Chaer, Abdul. 2009. Psikolingusitik. Jakarta: Rineka Cipta.

Darmansyah. 2011. Strategi Pembelajaran Menyenangkan Dengan Humor. Jakarta: Bumi Aksara.

Sudaryanto. 1993. Metode dan Aneka Teknik Analisis Bahasa. Yogyakarta: Duta Wacana University Press.

Seandainya. 2014. "Dua Laki-Laki Pejaka". Diunduh, 13Agustus2016.http://thecom mentnettv.blogspot.co.id/

UMM, Perpustakaan. 2016. “Analisis Bahasa Plesetan dalam Tayangan The Comment di Net TV". Diunduh, 26 Januari 2017. http://eprints.umm.ac.id/2200 2/

Waskitarini, Anindita. 2012. "Kajian Prinsip Kerja Sama yang Terjadi dalam Acara Komedi Opera Van Java di Trans 7'”. Diunduh, 23 Juli 2016 Journal.student.uny.ac.id/jurna 